\title{
Osteoporosis Care Following Incidental Vertebral Fractures: a Retrospective Cohort Study
}

J Gen Intern Med 36(6):1797-8 DOI: $10.1007 / \mathrm{s} 11606-020-05858-3$

(c) Society of General Internal Medicine 2020

\section{INTRODUCTION}

Osteoporosis is a worldwide disease with an increasing incidence that affects a large number of older adults. Vertebral compression fractures are the most common type of osteoporotic fracture, accounting for 700,000 of the 1.5 million osteoporotic fractures per year in the USA. ${ }^{1}$ Only one-third of vertebral compression fractures are symptomatic. ${ }^{2}$ After an initial vertebral fracture, a patient is at increased risk for hip fracture and is five times more likely to have another vertebral compression fracture in their lifetime. ${ }^{3}$ Unfortunately, even when a patient experiences a symptomatic fracture, rates of treatment with guideline-concordant therapy are very low $(3.3-45 \%){ }^{4-6}$ For the patients with asymptomatic, incidentally found fractures, we hypothesized that a formal diagnosis of osteoporosis as evidenced by appropriate follow-up care was unlikely. To explore this hypothesis, we reviewed the subsequent osteoporosis care of patients found to have incidental vertebral fractures.

\section{METHODS}

We performed a retrospective cohort study among patients with vertebral fractures noted on computed tomography $(\mathrm{CT})$ scans or X-rays of the chest, abdomen, or pelvis over a 5-year period (2013-2018) at a single Veterans Affairs academically affiliated hospital and evaluated subsequent osteoporosis care. Inclusion criteria were age $\geq 50$ and the word "compression" related to vertebral fractures in their imaging report. Patients were excluded if they had a previous history of osteoporosis or osteopenia, previous osteoporosis treatment, or an imaging indication of back pain or high level of trauma. Data was obtained from the VA Corporate Data Warehouse and manually extracted through algorithmic chart review by four reviewers. The primary outcome was occurrence of at least one of three osteoporosis-related care actions within 6 months: bone mineral density testing, endocrinology referral, or prescription of osteoporosis treatment medications.

Received March 5, 2020

Accepted April 13, 2020

Published online June 8, 2020

\section{RESULTS}

A total of 3181 imaging reports containing the word "compression" were reviewed, and after exclusions, 1839 reports were included in the final evaluation. Inter-rater reliability among reviewers using Fleiss' kappa was 0.83 for identifying inclusion and exclusion criteria and 0.74 for identifying subsequent osteoporosis care. Among eligible imaging reports, $99.02 \%$ of patients were male and the mean age was 70.61 years (Table 1). A total of 210 cases $(11.42 \%)$ received at least one intervention of the composite outcome; $7.61 \%$ received a DEXA scan; $5.98 \%$ received an endocrinology referral; and $7.72 \%$ received an osteoporosis medication prescription (Table 1). Among reports with vertebral compression in the impression section, adjusted frequency of follow-up intervention was $14.47 \%$ versus $10.07 \%$ for compression noted only in the body of the report section (odds ratio $=1.51$ [95\% CI 1.07-2.12], $p=0.02$, Table 2).

\section{DISCUSSION}

Our analysis demonstrates that most patients with an incidentally found vertebral compression fracture do not receive evaluation or treatment for osteoporosis in the following 6 months. The rates of subsequent osteoporosis care overall in this cohort were $11.42 \%$. For patients in whom the finding of compression is noted in the impression section of the

Table 1 Demographics, Imaging Report Characteristics, and Subsequent Osteoporosis-Related Care

\begin{tabular}{ll}
\hline \hline Variable & Description \\
\hline Eligible imaging reports, $n$ & 1839 \\
Patients, $n$ & 1185 \\
Male gender & $1821(99.02)$ \\
Age, mean (SD) & $70.61(9.63)$ \\
70 years old or older & $865(47.04)$ \\
Imaging type & \\
CT & $1011(54.98)$ \\
X-ray & $828(45.02)$ \\
Anatomic location of imaging & \\
Abdomen/pelvis & $608(33.06)$ \\
Chest & $1231(66.94)$ \\
Ordering service & \\
ED & $549(29.85)$ \\
Inpatient & $243(13.21)$ \\
Outpatient & $1047(56.93)$ \\
Compression finding highlighted in impression section & $455(24.74)$ \\
Subsequent osteoporosis-related care & $210(11.42)$ \\
DEXA scan & $140(7.61)$ \\
Endocrinology referral & $110(5.98)$ \\
Osteoporosis medication prescription & $142(7.72)$ \\
\hline
\end{tabular}

Values expressed as $n$ (\%) unless otherwise specified 
Table 2 Treatment Rates Based on Presence or Absence of Imaging Reports Characteristics

\begin{tabular}{|c|c|c|c|c|}
\hline \multirow[t]{2}{*}{$\begin{array}{l}\text { Imaging report } \\
\text { characteristic }\end{array}$} & \multicolumn{2}{|c|}{$\begin{array}{l}\text { Osteoporosis-related care } \\
\text { provided, \% (95\% CI) }\end{array}$} & \multirow{2}{*}{$\begin{array}{l}\text { Odds } \\
\text { ratio } \\
\text { (95\% } \\
\text { CI) }\end{array}$} & \multirow[t]{2}{*}{$p$} \\
\hline & $\begin{array}{l}\text { Reference } \\
\text { category }\end{array}$ & $\begin{array}{l}\text { Imaging report } \\
\text { characteristic } \\
\text { present }\end{array}$ & & \\
\hline $\begin{array}{l}70 \text { years old or } \\
\text { older } \\
\text { (reference }= \\
\text { younger than } 70 \\
\text { years old) }\end{array}$ & $\begin{array}{l}9.82(7.73- \\
12.42)\end{array}$ & $\begin{array}{l}16.13(13.38- \\
19.32)\end{array}$ & $\begin{array}{l}1.77 \\
(1.28- \\
2.44)\end{array}$ & $\begin{array}{l}< \\
0.001\end{array}$ \\
\hline $\begin{array}{l}\text { CT imaging } \\
\text { type } \\
\text { (reference }=\mathrm{X}- \\
\text { ray) }\end{array}$ & $\begin{array}{l}11.06 \\
(8.98- \\
13.55)\end{array}$ & $\begin{array}{l}11.37(9.32- \\
13.8)\end{array}$ & $\begin{array}{l}1.03 \\
(0.77- \\
1.38)\end{array}$ & 0.84 \\
\hline $\begin{array}{l}\text { Chest anatomic } \\
\text { location of } \\
\text { imaging } \\
\text { (reference = } \\
\text { abdomen } / \text { pelvis) }\end{array}$ & $\begin{array}{l}11.53 \\
(9.05- \\
14.58)\end{array}$ & $\begin{array}{l}11.09(9.3- \\
13.16)\end{array}$ & $\begin{array}{l}0.96 \\
(0.71- \\
1.29)\end{array}$ & 0.77 \\
\hline $\begin{array}{l}\text { Outpatient } \\
\text { ordering service } \\
\text { (reference = ED } \\
\text { or inpatient) }\end{array}$ & $\begin{array}{l}10.92 \\
(8.76- \\
13.54)\end{array}$ & $\begin{array}{l}11.45(9.47- \\
13.79)\end{array}$ & $\begin{array}{l}1.05 \\
(0.78- \\
1.42)\end{array}$ & .73 \\
\hline $\begin{array}{l}\text { Compression } \\
\text { finding } \\
\text { highlighted in } \\
\text { impression } \\
\text { section } \\
\text { (reference = not } \\
\text { highlighted) }\end{array}$ & $\begin{array}{l}10.07(8.4 \\
12.04)\end{array}$ & $\begin{array}{l}14.47(11.2- \\
18.51)\end{array}$ & $\begin{array}{l}1.51 \\
(1.07- \\
2.12)\end{array}$ & 0.02 \\
\hline
\end{tabular}

Values expressed as estimated marginal means (95\% CI) based on logistic regression models adjusted for remaining image report characteristics and using generalized estimation equations to account for correlation within subjects

imaging report, evaluation and treatment are significantly higher at $14.47 \%$, but still low overall.

To our knowledge, this is the largest evaluation of patients with incidental vertebral compression fractures and serves as a baseline for an opportunity to improve care. Strengths of the study include broad inclusion criteria, large data set, and reliable data collection through chart review with strong inter-rater reliability. There are several limitations to this study. First, it is possible that patients had previous trauma resulting in vertebral fractures, and therefore, we are overestimating the diagnosis of osteoporosis. Second, the electronic health record problem lists require manual entry of conditions and its use can be variable. Finally, the study population is predominantly male and could account for part of the low subsequent care rates seen in this cohort.

Despite these limitations, we believe that this analysis demonstrates a significant contribution to the osteoporosis literature and identifies a meaningful opportunity to diagnose and treat clinically "silent" osteoporosis. This study serves a robust baseline analysis that can inform health system interventions going forward. At a minimum, locating the finding of vertebral fracture in the impression section of the imaging report could have some impact on our patients.

\author{
Sean Bradley, $M D^{1,2}$ \\ Catey Harwell, $M D^{1,2}$ \\ Polina Kukhareva, $\mathrm{PhD}, \mathrm{MPH}^{2,3}$ \\ Peter Yarbrough, $M D^{1,2}$ \\ Sarah Knish Hall, $M D^{1,2}$ \\ ${ }^{1}$ Department of Internal Medicine, Division of General \\ Medicine, George E Wahlen Veterans Affairs \\ Medical Center, \\ Salt Lake City, UT, USA \\ ${ }^{2}$ Department of Internal Medicine, Division of General \\ Internal Medicine, University of Utah Medical \\ Center, \\ Salt Lake City, UT, USA \\ ${ }^{3}$ Department of Biomedical Informatics, University of \\ Utah School of Medicine, \\ Salt Lake City, UT, USA
}

Corresponding Author: Sean Bradley, MD; Department of Internal Medicine, Division of General Medicine, George E Wahlen Veterans Affairs Medical Center, Salt Lake City, UT, USA (e-mail: Bradley.sean.m@gmail.com).

\section{Compliance with Ethical Standards:}

Conflict of Interest: The authors declare that they do not have a conflict of interest.

\section{REFERENCES}

1. Riggs BL, Melton LJ III. The worldwide problem of osteoporosis: insights afforded by epidemiology. Bone. 1995; 17(Suppl):505S-511S

2. Fink HA, Milavetz DL, Palermo $\mathbf{L}$, et al. What proportion of incident radiographic vertebral deformities is clinically diagnosed and vice versa? J Bone Miner Res. 2005;20(7):1216-1222.

3. Cooper C. Epidemiology and public health impact of osteoporosis. Baillieres Clin Rheumatol. 1993;7(3):459-477.

4. Desai RJ, Mahesri M, Abdia Y, et al. Association of osteoporosis medication use after hip fracture with prevention of subsequent nonvertebral fractures: An instrumental variable analysis [published online July 20, 2018]. JAMA Netw Open.

5. Jennings LA, Auerbach AD, Maselli J, Pekow PS, Lindenauer PK, Lee SJ. Missed opportunities for osteoporosis treatment in patients hospitalized for hip fracture. J Am Geriatr Soc. 2010;58:650-657.

6. Elliot-Gibson V, Bogoch ER, Jamal SA, Beaton DE Practice patterns in the diagnosis and treatment of osteoporosis after a fragility fracture: a systematic review. Osteoporos Int. 2004;15(10):767-778. 